\title{
Outcome of late preterm newborns in Upper Egypt
}

\author{
Alkassem Algameel $^{1 *}$, Manal Elhawary' ${ }^{1}$ Sayed Amin ${ }^{1}$ and Marwa Abd Elmenem²
}

\begin{abstract}
Background: The incidence of preterm births is increasing and has become a global health concern. This study aimed to compare the outcome of late preterm (LPT) to full term (FT) neonates at two large hospitals in Upper Egypt.

Results: Out of 250 newborns included in the study, 180 (72\%) were FT and 70 (28\%) were LPT. More than half of the LPT newborns (52.9\%) were admitted to the neonatal intensive care unit (NICU), compared with $26.7 \%$ of FT newborns. Delivery of LPT was associated with an increased risk of neonatal morbidity, including jaundice requiring phototherapy (34.3\% vs. $7.8 \%$ ), respiratory morbidities ( $32.9 \%$ vs. $13.9 \%)$, hypoglycemia ( $8.6 \%$ vs. $1.7 \%)$, and convulsions ( $4.3 \%$ vs. $0.6 \%)$.

Conclusions: LPT neonates were more susceptible to suffer from jaundice and respiratory distress among other morbidities. They also had a higher rate of NICU admission, longer duration of NICU stay, as well as a higher mortality rate. The best treatment of late prematurity is to prevent it. Public and professional awareness of the problems associated with late prematurity should be highlighted. Follow-up programs for early detection and intervention for long term complications are recommended.
\end{abstract}

Keywords: Neonatal morbidity, Late preterm, Full term, Neonatal intensive care unit

\section{Background}

Gestational age has a major impact upon the clinical outcome of neonates. Therefore, it is necessary to standardize medical terminology related to neonatal maturation by gestational age rather than birth weight so that gestational age-appropriate care can be administered, and data from different studies can be compared. Term infants are defined as those with a gestational age 37 to 41 weeks [1]. According to the World Health Organization (WHO), the American Academy of Pediatrics (AAP), and the American College of Obstetricians and Gynecologists (ACOG), preterm birth is defined as the delivery of an infant before the completion of 37 weeks of gestation [2, 3].

\footnotetext{
* Correspondence: a.alkassem.algameel@gmail.com

'Pediatrics Department, Faculty of Medicine, Fayoum University, Fayoum, Egypt

Full list of author information is available at the end of the article
}

The incidence of preterm births is increasing in many countries around the world and has become a global health concern [4]. The National Center for Health Statistics of the Centers for Disease Control and Prevention generally reports data on three categories of preterm birth: overall preterm $(<37$ weeks' gestation), moderately preterm (between 32 and 36 weeks' gestation), and very preterm births $(<32$ weeks' gestation) [5]. Late preterm infants are born at a gestational age between 34 weeks and 0 day and 36 weeks and 6 days.

The LPT infants are recognized as the fastest increasing and largest proportion of singleton preterm births [6]. Data from the year 2010 have shown that LPT births accounted for 3.0 to $6.0 \%$ of live singleton births and constituted about 65 to $75 \%$ of preterm births [7]. The prevalence of LPT is affected by the rate of multiple births. While multiples constitute about $3 \%$ of all births,

(c) The Author(s). 2020 Open Access This article is licensed under a Creative Commons Attribution 4.0 International License, which permits use, sharing, adaptation, distribution and reproduction in any medium or format, as long as you give appropriate credit to the original author(s) and the source, provide a link to the Creative Commons licence, and indicate if changes were made. The images or other third party material in this article are included in the article's Creative Commons licence, unless indicated otherwise in a credit line to the material. If material is not included in the article's Creative Commons licence and your intended use is not permitted by statutory regulation or exceeds the permitted use, you will need to obtain permission directly from the copyright holder. To view a copy of this licence, visit http://creativecommons.org/licenses/by/4.0/. 
they accounted for about $20 \%$ of late preterm births and $5 \%$ of early term births [7-9].

They have higher morbidity and mortality rates than term infants due to their relative physiologic and metabolic immaturity, even though they are often the size and weight of some term infants $[10,11]$.

The period between 34 and 40 weeks of gestation is considered a critical growth period for the development of many neural structures and connections. Dramatic changes occur in brainstem development in terms of neuronal origin and proliferation, migration pathways, morphological and neurochemical differentiation, neurotransmitter receptors, neurotransmitters and enzymes, dendritic arborization, spinal formation, synaptogenesis, axonal growth, and myelination. In addition, cortical volume increases by $50 \%$ during this time. Therefore, the occurrence of brain injury during this critical period of neural development might affect late cerebral development [12].

Moreover, the development of other body systems and chemical pathways is affected by prematurity. The development of the terminal respiratory sacs and alveoli continues through gestational weeks 34 and 36 and the surfactant surge takes place at 34 weeks. Therefore, preterm infants suffer from delayed pulmonary maturation and are at an increased risk of respiratory distress syndrome (RDS), particularly when mothers have not administered antenatal steroids [13, 14]. In addition, late preterm infants suffer from a delay in the development of hepatic bilirubin conjugation pathways [15],have less brown adipose tissue to generate heat and less white adipose tissue for insulation [13], and are immunologically immature [16].

Many obstetric decisions during the final weeks of a pregnancy involve weighing the risks and benefits of delivering the infant prematurely against the risks and benefits of extending the pregnancy. For fully informed decision-making, an accurate understanding of the risks related to either choice is necessary. The studies of complications during birth showed substantial increases in the risks of morbidity and death for LPT infants, compared with term infants [17]. However, short- and longterm outcomes of LPT infants have not been adequately studied as the outcomes of extremely preterm newborns [6]. Meanwhile, the public health impact of LPT births is probably as great as or greater than that of early or moderate preterm births because of the increasingly larger rates of LPT births [17]. Therefore, the aim of the present study was to identify the outcome and clinical complications associated with LPT newborns as compared with FT newborns.

\section{Methods}

\section{Study population and settings}

This study included a cohort of 250 neonates born in Fayoum University Hospital and Beni Suef General
Hospital during 6 consecutive months (May 2018 to November 2018).

The study subjects were divided into two groups: group I, including late preterm neonates (full 34 to 36 weeks and 6 days) and group II, including full term neonates (from 37 to 40 weeks and 6 days).

\section{Inclusion criteria}

All singleton, live birth, and neonates of both sexes who were born in Fayoum University Hospital or Beni Suef General Hospital during the study period were included, whether born as late preterm or at full term.

\section{Exclusion criteria}

Neonates were excluded from the study if they were twins or multiple pregnancies, had major congenital and/or chromosomal anomalies, were suspected to have inborn error of metabolism, were born before 34 weeks or after 41 weeks of gestation or were still birth.

\section{Data collection}

Data for each subject were collected from hospitals' files and included the following:

History including maternal and gestational variables such as maternal age at the infant's birth, parity and gravidity, prior history of abortions, still births or premature deliveries, type of delivery, current clinical status observed during gestation including medical conditions (e.g., diabetes mellitus, hypertension, urinary tract infection), premature rupture of membrane $(\mathrm{PROM})>18 \mathrm{~h}$ before delivery, placental abruption, umbilical cord pathologies (e.g., cord coiling, true knot, cord prolapse), fever or rash, drug intake during pregnancy, heart disease, and other diseases. Also, we included data regarding neonatal variables such as sex, birth weight, gestational age (calculated from date of last menstruation and early obstetric ultrasonography), and resuscitation in delivery room.

Physical examination including 1 and 5-min Apgar scores, gestational age assessment by Ballard score, anthropometric measurements (circumference of head and length), general examination (integument, head and neck, eye, chest, heart, abdomen examination), and examination of neonatal reflexes.

Investigations including complete blood count, C-reactive protein, random blood glucose, serum calcium (total/ionized), electrolytes, bilirubin, arterial blood gases, chest XRay, echocardiography, and CT scan of the brain.

\section{Outcome measures}

The studied outcome measures included the pattern of feeding, admission to NICU, as well as the duration of hospitalization and readmission within neonatal period, neonatal morbidity, and neonatal mortality. Neonatal morbidities comprised the following: (a) respiratory 
morbidity (transient tachypnea of the newborn, hyaline membrane disease, pneumonia, pulmonary hypertension, apnea of prematurity, need for mechanical ventilation), (b) hyperbilirubinemia requiring phototherapy or blood exchange, (c) hypoglycemia (glucose below $40 \mathrm{mg} / \mathrm{dL}$ ), (d) hypothermia (body temperature below $36^{\circ} \mathrm{C}$ ) or hyperthermia, (e) sepsis or necrotizing enterocolitis, and (f) neurological manifestations (e.g., convulsions, intraventricular hemorrhage).

\section{Statistical analysis}

The collected data were statistically analyzed using the Statistical Package for the Social Science software, version 18 (SPSS Inc, USA). For quantitative data, KolmogorovSmirnov (KS) test was performed to evaluate the distribution of data. Variables that followed normal distribution were summarized as mean and standard deviation; independent samples $t$ test was used to compare between two groups and one-way analysis of variance (ANOVA) to compare between more than two. Variables that were not normally distributed were summarized as the median and range; Mann-Whitney- $U$ test was used to compare between two groups. Qualitative data were presented as number and percentages; chi square or Fisher's exact test were used to study the association between categorical variables. Statistical significance was considered at $p<0.05$.

\section{Results}

This cohort study included 250 newborns; out of them, 70 were LPT neonates, while 180 were FT neonates born at Fayoum University Hospital and Beni Suef General Hospital.

Table 1 shows the characteristics of the studied neonates and their mothers. The mean gestational age of the studied neonates was $35.7 \pm 0.8$ in the LPT and 39.1 \pm 1.0 in the FT neonates. There were no statistically significant differences of gender distribution among groups. The LPT neonates were born with significantly lower mean birth weight, length, and head circumference than the FT group $(p<0.001)$. Compared with the FT group, a significantly higher percentage of LPT was small for GA $(11.4 \%$ vs. $2.2 \%$, respectively; $p=0.002)$ and had microcephaly $(4.3 \%$ vs. $0.6 \% ; p=0.038)$.

Also, that the mean age of mothers of LPT neonates was $27.3 \pm 6.9$ years compared with $26.3 \pm 6.7$ of FT ones. The percentage of mothers in extremes of age ( $\leq 17$ years and $\geq 35$ years) were significantly higher in the LPT group $(5.7 \%$ vs. $0.56 \%$ and $21.4 \%$ vs. $8.34 \% ; p=0.001)$. Mothers of LPT neonates had history of more previous preterm delivery compared with mothers of FT ones $(14.3 \%$ vs. $6.1 \%$; $p=0.036)$. History of repeated abortion was higher among mothers of LPT neonates $(p=0.025)$ where $8.6 \%$ of them reported abortion for two times. Regarding maternal morbidities during pregnancy, hypertension was found in $27.1 \%$ of mothers of LPT compared with $14.4 \%$ of those of FT ones with a statistically significant difference $(p=0.012)$. Hypertensive mothers had an increased risk of LPT delivery than those with normal blood pressure by about two folds $\{\mathrm{OR}(95 \% \mathrm{CI})=2.21(1.13-4.32)\}$. There were no statistically significant differences between both groups regarding history of other diseases or parity.

Table 2 demonstrates the history of delivery. Vaginal delivery was significantly higher among FT neonates (60.6\%) compared with the LPT group, where cesarean section $(\mathrm{CS})$ was predominant $(64.3 \% ; p<0.0001)$. Vaginal delivery was indicated in full term mothers mainly due to onset of labor (53.9\%), while it was mainly either due to onset of labor (28.6\%), PROM (27.1\%) or fetal distress (21.4\%) in LPT group, with a statistically significant difference between both groups ( $p$ value $<0.001$ ) Compared with FT group, significantly $(p<0.001)$ higher percentage of LPT cases were delivered by CS mainly due to breech presentation $(35.7 \%$ vs. $8.3 \%)$ or previous CS (21.4\% vs. 13.9\%). Increased risk of LPT delivery was associated with placental abruption, fetal distress, and history of PROM $>18 \mathrm{~h}$ by about 11,4 , and 2 folds, respectively.

Table 3 compared the clinical condition and outcome between the studied LPT and FT neonates. The Apgar score after 1 and $5 \mathrm{~min}$ showed significantly lower means among LPT neonates $(5.2 \pm 1.7$ after 1 min and $7.7 \pm 1.5$ after $5 \mathrm{~min}$ ) with $p=0.015$ and 0.033 , respectively. There was an increased risk of low Apgar score $(<7)$ in LPT neonates than FT group by more than four times $\{\mathrm{OR}(95 \% \mathrm{CI})=4.93$ (2.17-11.18)\}. Formula feeding rate was significantly higher in the LPT group $(61.4 \%$ vs. $10.6 \% ; p<0.001)$.

A significantly higher percentage of LPT neonates was admitted to NICU $(52.9 \%$ vs. $26.7 \% ; p<0.001)$ with a statistically significant longer duration of admission (6.9 \pm 2.4 vs. $4.25 \pm 1.9$ days; $p<0.001$ ). The LPT neonates had an increased risk of NICU admission by about three folds than FT neonates $\{\mathrm{OR}(95 \% \mathrm{CI}=3.08(1.74-5.47)\}$. There was no statistically significant difference between the two groups regarding readmission. As regards the indications of NICU admission, significantly higher percentage of LPT neonates were admitted due to respiratory diseases $(32.9 \%$ vs. $13.9 \% ; p<0.001)$, jaundice (34.3\% vs. $7.8 \% ; p<0.001)$, hypoglycemia $(8.6 \%$ vs. $1.7 \%$; $p=0.009)$, and convulsions ( $4.3 \%$ vs. $0.6 \% ; p=0.038)$. The LPT neonates had 6 times higher risk of neonatal jaundice $\{\mathrm{OR}(95 \% \mathrm{CI}=6.19(2.96-12.91)\}$ and more than 5 times higher risk of hypoglycemia $\{\mathrm{OR}(95 \% \mathrm{CI}=5.53$ (1.342-2.77)\} as compared with FT. A significantly higher mortality rate was observed in LPT group (3 cases, $4.3 \%$ ) compared with FT group (1 case, $0.6 \% ; p=0.035$ ). The 
Table 1 Characteristics of neonates and mothers in the study groups ( $n=250$ )

\begin{tabular}{|c|c|c|c|c|}
\hline Variable & Late preterm $(n=70)$ & Full term $(n=180)$ & $p$ & Odds ratio for preterm $(95 \% \mathrm{Cl})$ \\
\hline \multicolumn{5}{|c|}{ Gestational age (weeks) } \\
\hline Median (IQR) & $35.9(35.0-36.4)$ & $39.0(38.3-39.9)$ & $<0.001(Z)^{*}$ & \\
\hline \multicolumn{5}{|l|}{ Sex } \\
\hline Male & $31(44.3 \%)$ & $80(44.4 \%)$ & $0.982\left(x^{2}\right)$ & \\
\hline Female & $39(55.7 \%)$ & $100(55.6 \%)$ & & \\
\hline \multicolumn{5}{|l|}{ Birth weight } \\
\hline Mean \pm SD & $2310.7 \pm 361.9$ & $3147.4 \pm 608.3$ & $<0.001(t)^{*}$ & \\
\hline SGA & $8(11.4 \%)$ & $4(2.2 \%)$ & $0.002\left(x^{2}\right)^{*}$ & \\
\hline LGA & $1(1.4 \%)$ & $13(7.2 \%)$ & & \\
\hline \multicolumn{5}{|l|}{ Length } \\
\hline Mean \pm SD & $45.6 \pm 5.6$ & $48.3 \pm 1.8$ & $<0.001(t)^{*}$ & \\
\hline \multicolumn{5}{|l|}{$\mathrm{HC}$} \\
\hline Mean \pm SD & $31.8 \pm 1.4$ & $33.8 \pm 1.4$ & $<0.001(t)^{*}$ & \\
\hline Microcephaly & $3(4.3 \%)$ & $1(0.6 \%)$ & $0.038\left(x^{2}\right)^{*}$ & \\
\hline Macrocephaly & $1(1.4 \%)$ & $2(1.1 \%)$ & $0.843\left(x^{2}\right)$ & \\
\hline \multicolumn{5}{|c|}{ Age at delivery (years) } \\
\hline$<17$ & $4(5.7 \%)$ & $1(0.6 \%)$ & $0.001\left(x^{2}\right)^{*}$ & \\
\hline $17-34$ & $51(72.9 \%)$ & $164(91.1 \%)$ & & \\
\hline$\geq 35$ & $15(21.4 \%)$ & $15(8.3 \%)$ & & \\
\hline \multicolumn{5}{|l|}{ Parity } \\
\hline Primigravida & $17(24.3 \%)$ & $57(31.7 \%)$ & $0.283\left(x^{2}\right)$ & \\
\hline Multigravida & $53(75.7 \%)$ & $123(68.3 \%)$ & & \\
\hline \multicolumn{5}{|c|}{ Previous preterm delivery } \\
\hline Yes & $10(14.3 \%)$ & $11(6.1 \%)$ & $0.036\left(x^{2}\right)^{*}$ & \\
\hline \multicolumn{5}{|l|}{ Abortion } \\
\hline No & $46(65.7 \%)$ & $119(66.1 \%)$ & $0.025\left(x^{2}\right)^{*}$ & \\
\hline One time & $18(25.7 \%)$ & $58(32.2 \%)$ & & \\
\hline Two times & $6(8.6 \%)$ & $3(1.7 \%)$ & & \\
\hline \multicolumn{5}{|c|}{ Antenatal care visits at last pregnancy } \\
\hline Yes & $50(71.4 \%)$ & $138(76.6 \%)$ & $0.578\left(x^{2}\right)$ & \\
\hline Mean \pm SD & $3.7 \pm 1.9$ & $3.9 \pm 2.1$ & $0.512(t)$ & \\
\hline \multicolumn{5}{|l|}{ Medical diseases } \\
\hline DM & $6(8.6 \%)$ & $18(10.0 \%)$ & $0.736\left(x^{2}\right)$ & $0.84(0.32-2.22)$ \\
\hline Hypertension & $19(27.1 \%)$ & $26(14.4 \%)$ & $0.012\left(x^{2}\right)^{*}$ & $2.21(1.13-4.37)$ \\
\hline UTI & $19(27.1 \%)$ & $38(21.1 \%)$ & $0.309\left(x^{2}\right)$ & $1.39(0.74-2.63)$ \\
\hline Fever/rash & $6(8.6 \%)$ & $7(3.9 \%)$ & $0.133\left(x^{2}\right)$ & $2.32(0.75-7.16)$ \\
\hline Cardiac & $1(1.4 \%)$ & $1(0.6 \%)$ & $0.123\left(x^{2}\right)$ & $2.59(0.16-42.05)$ \\
\hline Respiratory & $3(4.3 \%)$ & $3(1.7 \%)$ & $0.230\left(x^{2}\right)$ & $2.64(0.52-13.41)$ \\
\hline
\end{tabular}

IQR interquartile range, $S D$ standard deviation, $t$ independent samples $t$ test, UTI urinary tract infection, $X^{2}$ chi square test for independence, $Z$ Mann-Whitney test *Significant $p$ value $<0.05$

causes of death were necrotizing enterocolitis in two cases and apnea of prematurity in the third.

Figures 1 and 2 show the respiratory diseases that were found in the studied neonates and the type of oxygen support that was used. Respiratory distress syndrome
(RDS, $72 \%$ of cases with respiratory disease) and pneumonia (8.7\%) were more frequent in LPT neonates, while in FT neonates, transient tachypnea of the newborn was the commonest cause for respiratory distress ( $84 \%$ of cases with respiratory diseases). The need for 
Table 2 Delivery characteristics of mothers of the studied groups $(n=250)$

\begin{tabular}{|c|c|c|c|c|}
\hline Variable & Late preterm $(n=70)$ & Full term $(n=180)$ & $p$ & Odds ratio for preterm $(95 \% \mathrm{Cl})$ \\
\hline \multicolumn{5}{|l|}{ Mode of delivery } \\
\hline Vaginal & $25(35.7 \%)$ & $109(60.6 \%)$ & $<0.001\left(x^{2}\right)^{*}$ & $2.76(1.56-4.90)$ \\
\hline Cesarean section & $45(64.3 \%)$ & 71 (39.4\%) & & \\
\hline \multicolumn{5}{|l|}{ Indication of delivery } \\
\hline Onset of delivery & $20(28.6 \%)$ & 97 (53.9\%) & $<0.001\left(x^{2}\right)^{*}$ & $0.34(0.19-0.62)$ \\
\hline History of PROM & $19(27.1 \%)$ & 35 (19.4\%) & & $1.54(0.81-2.94)$ \\
\hline Placental abruption & $8(11.4 \%)$ & $2(1.1 \%)$ & & $11.48(2.37-55.54)$ \\
\hline Umbilical cord pathology & $8(11.4 \%)$ & $36(20.0 \%)$ & & $0.44(0.20-1.01)$ \\
\hline Fetal distress & $15(21.4 \%)$ & $10(5.6 \%)$ & & $4.64(1.97-10.91)$ \\
\hline \multicolumn{5}{|l|}{ Indication of cesarean section } \\
\hline Breech presentation & $25(35.7 \%)$ & $15(8.3 \%)$ & $<0.001\left(x^{2}\right)^{*}$ & \\
\hline Previous cesarean section & $15(21.4 \%)$ & 25 (13.9\%) & & \\
\hline Placenta previa & $5(7.1 \%)$ & $16(8.9 \%)$ & & \\
\hline Elective cesarean section & $0(0.0 \%)$ & $15(8.3 \%)$ & & \\
\hline
\end{tabular}

ventilation was significantly higher in LPT neonates (56.5\% vs. 20\%; $p=0.009$ ). CPAP and head box were more frequently used in LPT neonates $(43.4 \%$ and $47.8 \% ; p=0.036$ and $=0.018$, respectively).

Table 4 summarizes the results of laboratory investigations in the studied neonates. The mean values of WBCs and platelet count were significantly lower in LPT neonates compared with FT group ( $p=0.031$ and 0.002 , respectively). The mean value of CRP was higher in LPT $7.4 \pm 20.6$ compared with $1.6 \pm 9.2$ for FT ones ( $p$ value $<0.026)$. The mean values of calcium (total, ionized) and random blood sugar were significantly lower in LPT neonates compared with FT group $(p<0.001)$. Total and direct bilirubin were analyzed in 150 neonates (50 LPT and $100 \mathrm{FT}$ ); $40.0 \%$ of LPT infant and $11.0 \%$ of FT had elevated bilirubin from their second day of life and required phototherapy. Also $8 \%$ of LPT infant (6\% due to $\mathrm{ABO}$ incompatibility and $2 \%$ due to $\mathrm{RH}$ incompatibility) and $3.0 \%$ of FT (2\% due to ABO incompatibility and $1 \%$ due to $\mathrm{RH}$ incompatibility) had jaundice from their first day of life and needed NICU admission.

The LPT neonates were then subdivided into three subgroups: those born between 34 weeks of gestation and before the 35th week; those born between the 35 th week of gestation and the 36th week; and neonates born between 36 weeks of gestation and before the 37 th week. Table 5 displays the comparison between the three subgroups. There was no significant difference among the three subgroups as regards Apgar scores at 1 and $5 \mathrm{~min}$ ( $p=0.0141$ and 0.220 , respectively), percentage of NICU admission $(p=0.060)$, as well as incidence of jaundice $(p$ $0.347)$, hypothermia $(p=0.279)$, sepsis $(p=0.874$ and 0.842 for early and late, respectively), hypoglycemia ( $p=$
$0.758)$, hypocalcemia ( $p$ 0.836), convulsions $(p=0.748)$, bleeding disorders $(p=0.651)$, and mortality $(p=0.289)$. A significantly higher number of LPT neonates born between 36th and 37th weeks had lower incidence of respiratory diseases, compared with the other two subgroups $(p<0.001)$. The duration of NICU stay was significantly lower in neonates born between the 36th and 37th weeks compared with those in the other two subgroups that were born earlier.

\section{Discussion}

The growing interest about late preterm newborns in the medical literature encouraged us to conduct this study to evaluate the outcome and clinical complications that could be associated with LPT compared with FT newborns. Our study was conducted on 250 neonates born in Fayoum University Hospital and Beni-Suef General Hospital. Out of them, 70 were LPT and 180 were FT neonates.

We found no statistically significant association between the gender of neonates and LPT delivery. This was in agreement with Teoh et al. [18] However, several earlier studies [19-22] reported an increased risk of preterm delivery associated with male fetus. Wilms et al. [21] suggested an effect of maternal race on the association between gender and preterm delivery. The postulated explanations for this association included that placental or chorionic trophoblastic cells of the male fetus produce more pro-inflammatory TNF $\alpha$ and lesser anti-inflammatory IL-10 and granulocyte colony stimulating factor than cells from pregnancies with a female fetus, resulting in the generation of a more proinflammatory intrauterine environment. Also, differences 
Table 3 Outcome of the studied neonates $(n=250)$

\begin{tabular}{|c|c|c|c|c|}
\hline Variable & Late preterm $(n=70)$ & Full term $(n=180)$ & $p$ & Odds ratio for outcome $(95 \% \mathrm{Cl})$ \\
\hline \multicolumn{5}{|l|}{ Apgar score } \\
\hline At 1 min mean \pm SD & $5.2 \pm 1.7$ & $5.7 \pm 1.2$ & $0.015(t)^{*}$ & \\
\hline At 5 min mean $\pm S D$ & $7.7 \pm 1.5$ & $9.1 \pm 1.1$ & $0.033(t)^{*}$ & $4.93(2.17-11.18)$ \\
\hline \multicolumn{5}{|l|}{ Feeding pattern } \\
\hline Breast & $13(18.6 \%)$ & $100(55.6 \%)$ & $<0.001\left(x^{2}\right)^{*}$ & \\
\hline Formula & $43(61.4 \%)$ & $19(10.6 \%)$ & & \\
\hline Mixed & $14(20.0 \%)$ & 61 (33.9\%) & & \\
\hline \multicolumn{5}{|l|}{ NICU admission } \\
\hline Yes & $37(52.9 \%)$ & $48(26.7 \%)$ & $<0.001\left(x^{2}\right)^{*}$ & $3.08(1.74-5.47)$ \\
\hline \multicolumn{5}{|l|}{ Duration of admission (days) } \\
\hline Mean \pm SD & $6.9 \pm 2.4$ & $4.3 \pm 1.9$ & $<0.001(t)^{*}$ & \\
\hline \multicolumn{5}{|l|}{ Readmission } \\
\hline Yes & $3(4.3 \%)$ & $4(2.2 \%)$ & $0.375\left(x^{2}\right)$ & \\
\hline \multicolumn{5}{|l|}{ Mortality } \\
\hline Yes & $3(4.3 \%)$ & $1(0.6 \%)$ & $0.035\left(x^{2}\right)^{*}$ & \\
\hline \multicolumn{5}{|l|}{ Indications of NICU admission } \\
\hline Respiratory diseases & $23(32.9 \%)$ & $25(13.9 \%)$ & $<0.001\left(x^{2}\right)^{*}$ & \\
\hline Neonatal jaundice & $24(34.3 \%)$ & $14(7.8 \%)$ & $<0.001\left(x^{2}\right)^{*}$ & \\
\hline Phototherapy duration for jaundice (days) & $3.9 \pm 1.6$ & $3.8 \pm 1.4$ & $0.492(t)$ & \\
\hline Hypothermia & $3(4.3 \%)$ & $0(0.0 \%)$ & & \\
\hline Early onset sepsis & $2(2.9 \%)$ & $1(0.6 \%)$ & $0.141\left(x^{2}\right)$ & \\
\hline Late onset sepsis & $6(8.6 \%)$ & $8(4.4 \%)$ & $0.194\left(x^{2}\right)$ & \\
\hline Hypoglycemia & $6(8.6 \%)$ & $3(1.7 \%)$ & $0.009\left(x^{2}\right)^{*}$ & \\
\hline Hypocalcemia & $5(7.1 \%)$ & $5(2.8 \%)$ & $0.119\left(x^{2}\right)$ & \\
\hline Convulsions & $3(4.3 \%)$ & $1(0.6 \%)$ & $0.038\left(x^{2}\right)^{*}$ & \\
\hline Bleeding tendency & $2(2.9 \%)$ & $1(0.6 \%)$ & $0.141\left(x^{2}\right)$ & \\
\hline Congenital heart disease & $3(4.3 \%)$ & $5(2.8 \%)$ & $0.546\left(x^{2}\right)$ & \\
\hline
\end{tabular}

$S D$ standard deviation, $t$ independent samples $t$ test, $X^{2}$ chi square test for independence

*Significant $p$ value $<0.05$

in gene expressions between placentae of male and female fetuses have been proposed as an explanation for male gender predominance in preterm labor [20].

In the present study, mothers at the extremes of reproductive age have a higher risk of preterm labor. The incidence of late preterm labor was significantly the highest among mothers who were less than 17 years of age, where $80 \%$ of them gave birth before 37 weeks of gestation, and the prevalence was also high $(50 \%)$ when the maternal age was more than 35 years old. In agreement to our results, Carter et al. [23] found that maternal age $\leq 17$ and $\geq 35$ was associated with increased risk of LPT birth. Kozuki et al. [24] conducted a metaanalysis to study the association of maternal age with preterm delivery and neonatal outcome, and they found that the nulliparous women with age $<18$ had the highest risk of preterm birth followed by multiparous women aged $\geq 35$ years.
In our study, we did not find any significant association of LPT birth with parity, which is in line with the data reported by a case-control study in 5 Italian Centers [25]. However, in a study conducted over 10 years to estimate outcomes of LPT deliveries, a significantly increased prevalence of late preterm birth in multiparous patient was reported [26].

Comparison between LPT births and FT births in the present study indicated that mothers of LPT neonates were more likely to have had a previous preterm birth, which agrees with results reported by McDonald and his colleagues [27].

Till today, there is a controversy regarding the association between previous abortions and the risk of LPT birth. A systematic review [28] defined that, out of 24 considered papers, 12 reported an increased risk of preterm birth among women with previous abortions. In the present study, there was a significant association 

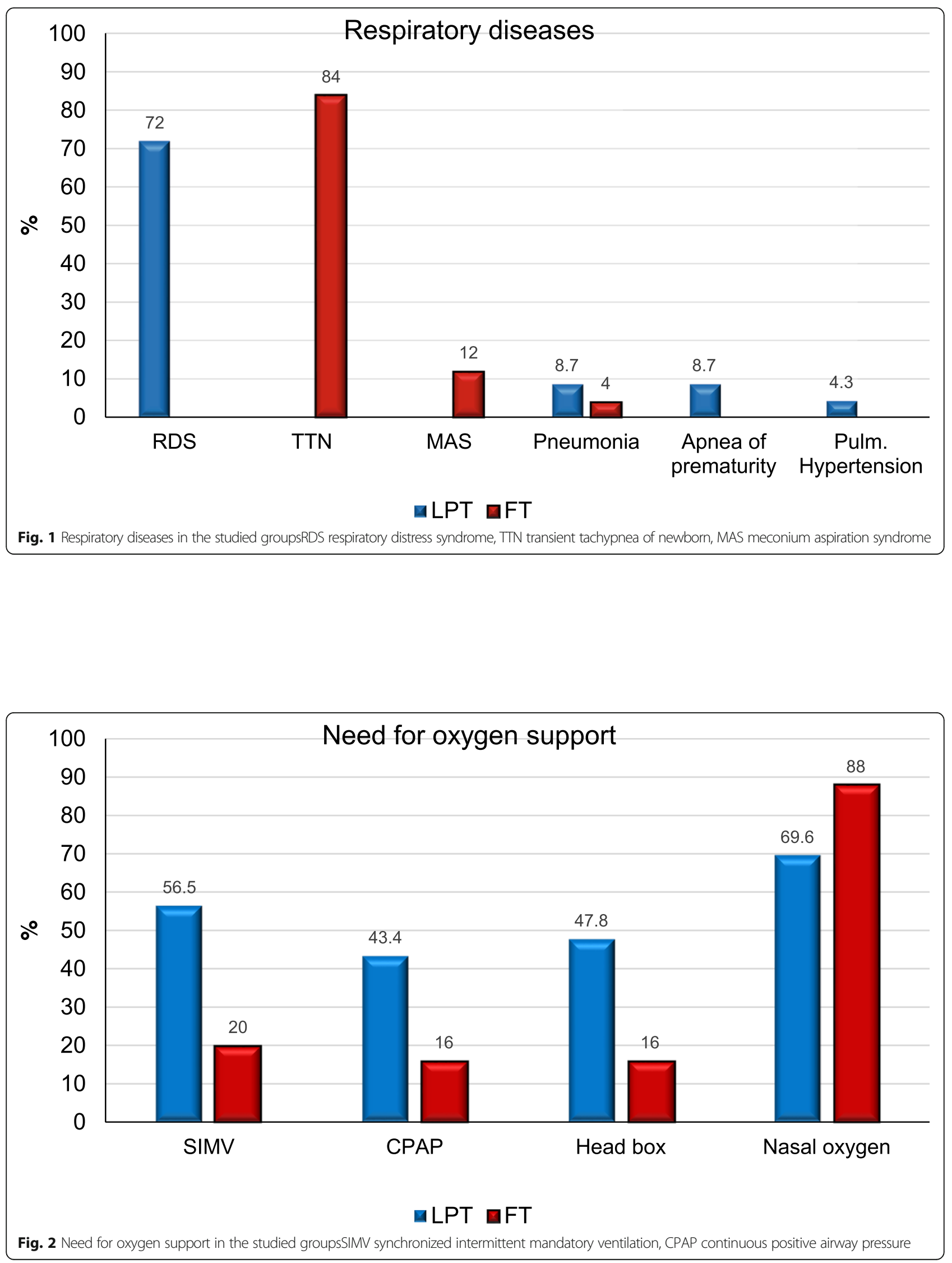
Table 4 Laboratory investigations done to studied groups

\begin{tabular}{|c|c|c|c|}
\hline & Late preterm & Full term & $p$ \\
\hline \multicolumn{4}{|l|}{$\mathrm{HB}(\mathrm{gm} / \mathrm{dl})$} \\
\hline Mean \pm SD & $13.7 \pm 2.7$ & $13.4 \pm 1.9$ & $0.398(t)$ \\
\hline \multicolumn{4}{|l|}{ WBCs $\left(10^{3} / \mathrm{mm}\right)$} \\
\hline Mean \pm SD & $8.3 \pm 2.6$ & $10.8 \pm 1.2$ & $0.031(t)^{*}$ \\
\hline \multicolumn{4}{|c|}{ Platelets $\left(10^{3} / \mathrm{mm}\right)$} \\
\hline Mean \pm SD & $237.2 \pm 66.4$ & $265.5 \pm 62.6$ & $0.002(t)^{*}$ \\
\hline \multicolumn{4}{|l|}{ CRP (mg/l) } \\
\hline Mean \pm SD & $7.4 \pm 20.6$ & $1.6 \pm 9.2$ & $0.026(t)^{*}$ \\
\hline \multicolumn{4}{|l|}{ Ca total (mg/dl) } \\
\hline Mean \pm SD & $8.7 \pm 0.5$ & $8.9 \pm 0.4$ & $<0.001(t)^{*}$ \\
\hline \multicolumn{4}{|c|}{ Ca ionized (mg/dl) } \\
\hline Mean \pm SD & $4.8 \pm 0.3$ & $4.9 \pm 0.3$ & $<0.001(t)^{*}$ \\
\hline \multicolumn{4}{|l|}{ RBS (mg/dl) } \\
\hline Mean \pm SD & $67.3 \pm 15.1$ & $75.1 \pm 10.9$ & $<0.001(t)^{*}$ \\
\hline \multicolumn{4}{|c|}{ Total bilirubin (mg/dl) } \\
\hline Mean \pm SD & $10.6 \pm 3.8$ & $9.9 \pm 2.8$ & $0.183(t)$ \\
\hline \multicolumn{4}{|c|}{ Direct bilirubin (mg/dl) } \\
\hline Mean \pm SD & $0.7 \pm 0.3$ & $0.6 \pm 0.3$ & $0.890(t)$ \\
\hline
\end{tabular}

$S D$ standard deviation, $t$ independent samples $t$ test

*Significant $p$ value $<0.05$

between LPT birth and having more than 1 previous abortion.

Several maternal medical conditions, including hypertensive disorders of pregnancy, diabetes, and asthma, have been associated with an increased risk for indicated or spontaneous preterm birth. In the present study, we found an increased incidence of LPT birth with hypertension, while it was not statistically different for gestational diabetes, urinary tract infection, cardiac, or respiratory diseases. In partial agreement to our results, Carter et al. [23] found that comorbidities, particularly hypertension and gestational diabetes, have been associated with the risk of LPT birth.

The mode of delivery has been linked to the risk of LPT births. We found that LPT neonates were more likely to be delivered by cesarean section than FT neonates. The most frequent indications for cesarean sections in LPT neonates were breech presentation and previous cesarean section. None of the CS was elective or indicated for maternal comorbidities. Cesarean sections in preterm deliveries are known to pose increased risks of neonatal morbidity and mortality $[29,30]$.

We found that Apgar scores after $1 \mathrm{~min}$ and $5 \mathrm{~min}$ were significantly lower among LPT neonates. These findings were comparable to those reported by in an Indian tertiary care teaching hospital [31]. Also, LPT neonates had significantly lower birth weight and head circumference, which agrees with some earlier reports
$[12,32]$. Accordingly, the incidence of $11.4 \%$ of SGA was significantly higher in LPT neonates compared with the FT group; this was comparable to the results of Araújo et al. [33] as about one quarter of the LPT neonates in their study were SGA.

The outcome of the studied neonates has been evaluated in terms of the feeding pattern, the incidence of NICU admission, as well as neonatal and mortality. In the present study, the LPT neonates had a higher incidence of formula feeding compared with the FT group, which agrees with previous reports [34-36]. Some of the reasons postulated for poor breastfeeding included decreased alertness, poor latching on skills, decreased oromotor tone, disorganized sucking patterns, and poor suck/swallow coordination. The immature suction pressures produced may reduce lactogenesis [34, 35]. All these factors may result in difficulty in establishing maternal-infant bonding and the initiation/maintenance of successful breastfeeding. Feeding issues are of paramount importance in such cases; poor feeding can lead to decreased caloric intake and dehydration, which further exacerbate neonatal complications such as hypoglycemia, hyperbilirubinemia, respiratory distress, and temperature instability [37].

Our results showed that LPT neonates were more frequently admitted to NICU compared with FT neonates; however, no significant difference was observed in NICU readmissions. Moreover, we found that the lower the gestational age, the rate of NICU admission is increased, as there were $43.3 \%, 50 \%$, and $83.3 \%$ for infants born at 36,35 , and 34 weeks of gestation, respectively. Similar results were reported by Tsai and his colleagues [2], where $21 \%, 43 \%$, and $74 \%$ of their cases were to in NICU or special care nursery when born at 36, 35, and 34 weeks of gestation, respectively. Also, they found that hospital readmission rate was not different between LPT and FT neonates.

The duration of NICU stay in LPT neonates in our study was significantly longer than in FT neonates; the mean length of stay in NICU was significantly higher in neonates born at 34 weeks and 35 weeks than in those born at 36 weeks of gestation. Similarly, Hibbard and his colleagues [38] reported a statistically significant increase in both the incidence of NICU admission and duration of stay with decreased gestational age.

From our study, the mortality rate among LPT neonates was significantly higher than among the FT group; stratification of neonates by their GA revealed that the highest rates were among those born at 34th week of gestation, though statistical significance was not reached. In accordance with our findings, Hibbard and his colleagues [38] and Steure et al. [39] reported a significantly increasing mortality rate with the lowering of the gestation age. The lack of statistical significance in comparisons of the preterm 
Table 5 Indication for NICU admission in LPT subgroups

\begin{tabular}{|c|c|c|c|c|c|c|c|}
\hline Variable & $\begin{array}{l}34(0-6) \text { weeks } \\
(n=12)\end{array}$ & $\begin{array}{l}35(0-6) \text { weeks } \\
(n=28)\end{array}$ & $36(0-6)$ weeks $(n=30)$ & $p$ & $p 1$ & $p 2$ & p3 \\
\hline \multicolumn{8}{|l|}{ Apgar score (mean \pm SD) } \\
\hline At $1 \mathrm{~min}$ & $4.6 \pm 1.7$ & $5.5 \pm 1.6$ & $5.8 \pm 1.9$ & $0.141(F)$ & 0.303 & 0.119 & 0.792 \\
\hline At 5 min & $7.2 \pm 1.6$ & $7.7 \pm 1.8$ & $8.1 \pm 1.2$ & $0.220(F)$ & 0.614 & 0.206 & 0.584 \\
\hline \multicolumn{8}{|l|}{ NICU admission $n(\%)$} \\
\hline Yes & $10(83.3 \%)$ & $14(50.0 \%)$ & $13(43.3 \%)$ & $0.060\left(x^{2}\right)$ & 0.105 & 0.019 & 0.611 \\
\hline \multicolumn{8}{|c|}{ Duration of admission (mean \pm SD) } \\
\hline Days & $7.1 \pm 1.9$ & $8.4 \pm 2.6$ & $5.2 \pm 1.2$ & $0.001\left(x^{2}\right)^{*}$ & 0.147 & $0.018^{*}$ & $<0.001^{*}$ \\
\hline \multicolumn{8}{|l|}{ Readmission $n(\%)$} \\
\hline Yes & $1(8.3 \%)$ & $1(3.6 \%)$ & $1(3.3 \%)$ & $0.944\left(x^{2}\right)$ & 0.874 & 0.909 & 0.503 \\
\hline \multicolumn{8}{|l|}{ Mortality $n(\%)$} \\
\hline Yes & $2(16.7 \%)$ & $1(3.6 \%)$ & $0(0.0 \%)$ & $0.289\left(x^{2}\right)$ & 0.432 & 0.136 & 0.975 \\
\hline \multicolumn{8}{|l|}{ Indications of NICU admission } \\
\hline Respiratory diseases & $9(75.0 \%)$ & $12(42.9 \%)$ & $2(6.7 \%)$ & $<0.001\left(x^{2}\right)^{*}$ & 0.060 & $<0.001^{*}$ & $<0.001^{*}$ \\
\hline Neonatal jaundice & $6(50.0 \%)$ & $10(35.7 \%)$ & $8(26.7 \%)$ & $0.347\left(x^{2}\right)$ & 0.622 & 0.277 & 0.457 \\
\hline $\begin{array}{l}\text { Phototherapy duration for } \\
\text { jaundice (days) }\end{array}$ & $4.3 \pm 2.8$ & $4.0 \pm 0.9$ & $3.5 \pm 0.5$ & $0.150(F)$ & 0.786 & 0.182 & 0.321 \\
\hline Hypothermia & $2(16.7 \%)$ & $1(3.6 \%)$ & $0(0.0 \%)$ & $0.279\left(x^{2}\right)$ & 0.432 & 0.136 & 0.974 \\
\hline Early onset sepsis & $1(8.3 \%)$ & $1(3.6 \%)$ & $0(0.0 \%)$ & $0.842\left(x^{2}\right)$ & 0.874 & 0.632 & 0.975 \\
\hline Late onset sepsis & $2(16.7 \%)$ & $2(7.1 \%)$ & $2(6.7 \%)$ & $0.886\left(x^{2}\right)$ & 0.730 & 0.677 & 0.655 \\
\hline Hypoglycemia & $2(16.7 \%)$ & $3(10.7 \%)$ & $1(3.3 \%)$ & $0.758\left(x^{2}\right)$ & 0.867 & 0.483 & 0.555 \\
\hline Hypocalcemia & $1(8.3 \%)$ & $2(7.1 \%)$ & $2(6.7 \%)$ & $0.836\left(x^{2}\right)$ & 0.600 & 0.636 & 0.655 \\
\hline Convulsions & $1(8.3 \%)$ & $2(7.1 \%)$ & $0(0.0 \%)$ & $0.748\left(x^{2}\right)$ & 0.600 & 0.632 & 0.442 \\
\hline Bleeding tendency & $0(0.0 \%)$ & $2(7.1 \%)$ & $0(0.0 \%)$ & $0.651\left(x^{2}\right)$ & 0.874 & 0.865 & 0.442 \\
\hline Congenital heart disease & $2(16.7 \%)$ & $1(3.6 \%)$ & $0(0.0 \%)$ & $0.279\left(x^{2}\right)$ & 0.432 & 0.136 & 0.975 \\
\hline
\end{tabular}

F one-way ANOVA test, NICU neonatal intensive care unit, SD standard deviation, $X^{2}$ chi square test for independence

*Significant $p$ value $<0.05$

subcategories may be attributed to the relatively small size of each subgroup. Moreover, a large population-based cohort study [40] from the USA and Canada showed that preterm infants are at high relative risks for infant death.

In our study, neonatal complications were more frequent in LPT compared with FT infants. The most common complications in the LPT group were neonatal jaundice (34.3\%) and respiratory diseases (32.9\%). In this study, the frequency of neonatal jaundice was significantly higher in LPT neonates compared with the FTs (34.3\% vs. 7.8\%). Similarly, Darcy [41] and Premji et al. [42] found that hyperbilirubinemia is the most common reason for admission in the LPT population $(41.4 \%$ vs. $12.9 \%$ and $38.4 \%$ vs. $7.2 \%$, respectively).

The most common cause of respiratory distress in LPTs was RDS (72\%). Our study results were analogous to those reported by Tsai and his colleagues [2], who reported more neonatal respiratory complication in the LPT than in FT neonates (33.4\% vs. 14.2\%). Also a study from Pakistan found that LPT newborns had an increased risk of RDS $(16.5-18.2 \%$ in LPTs vs. $0.3-2 \%$ in
FTs) [43]. The higher incidence of respiratory distress in LPT neonates could result from immaturity of their lungs [44].

Our results showed a higher need for ventilation in LPT compared with FT infants ( $56.5 \%$ vs. $20 \%)$, with significantly higher percentage requiring CPAP and head box in the LPT group. In a similar study, Hibbard and his colleagues [38] found that LPT neonates, particularly those delivered at 34 weeks, required more oxygen supplementation $(8.3 \%)$, intubation $(2.9 \%)$, and mechanical ventilation $(0.2 \%)$ in the delivery room than neonates born at each successive week gestational age.

We compared the incidence of neonatal jaundice and $\mathrm{RD}$ among different gestational ages, and it showed that the rate of jaundice increased with lowering of gestational age $(50 \%$ in the 34 th, $35.7 \%$ in the 35th, and $26.7 \%$ in the 36th weeks of gestation). Also, RD showed a similar trend $(75 \%$ in the 34th, $42.9 \%$ in the 35th, and $6.7 \%$ in the 36th weeks of gestation). Our results were comparable with those of Hibbard et al. [38] who found the rates of jaundice were $55 \%, 45.7 \%$, and $16.1 \%$ and 
those of RD were $50 \%, 45.2 \%$, and $22.5 \%$ in the 34th, 35th, and 36th weeks of gestation, respectively.

We found also that hypoglycemia was significantly higher in the LPT than the FT group, and it decreased with increased GA. Similarly, Marrocchella et al. [45] found a significantly higher incidence of hypoglycemia that decreased with the increase in GA in all LPT compared with FT neonates. This finding could be explained by the limited glycogen stores and rapid depletion of glucose stores from the metabolic demands of the newborn transition period. In addition, cold stress, poor suck/swallow ability, and respiratory complications contribute to the risk of developing hypoglycemia [41, 46]. Another probable explanation for the susceptibility to hypoglycemia in the LPT neonates is that most of those neonates were exposed to steroids during late pregnancy [47].

As regards late onset sepsis, our study revealed that the rate was higher, though non-significantly different, in the LPT compared with the FT group ( $8.6 \%$ vs. $4.4 \%)$; the rate followed an inverse relationship with the GA. In partial agreement to our results, Bailit et al. [48] reported a significantly higher rate of late onset sepsis in LPT infants $(9.9 \%$ vs. $1 \%$ ), with improvement in NICU admission and rate of cases for each week of gestation until 39 weeks.

In this study, convulsions were significantly higher in the LPT group compared with the FTs; the rate decreased with the increased GA. Comparable findings in neonates born from the 34th to the 39th weeks of gestation were reported by Glass et al. [49]. In addition, Tsai et al. [2] reported that a remarkable risk of neonatal neurological disorders, particularly seizure and periventricular leukomalacia, was noted in LPT neonates.

\section{Conclusions}

LPT compared with FT neonates were found more susceptible to jaundice and respiratory distress among other morbidities. They also had a higher rate of NICU admission, longer duration of NICU stay, and a higher mortality rate. The best treatment of late prematurity is to prevent it. Public and professional awareness of the problems associated with late prematurity should be highlighted. A multidisciplinary team including an obstetrician and a pediatrician is important for counseling women who have a need for early delivery, as well as in discouraging those without clear indications for early inductions or early planned cesarean deliveries. Every effort should be made to delay delivery of infants until at least 38 weeks'gestational age to decrease neonatal morbidity.

\section{Limitations}

Although conducted at 2 large hospitals, this study included only 250 subjects. Further research work at multiple centers to include different ethnic groups and larger number of participants may be needed.

\section{Abbreviations}

AAP: American Academy of Pediatrics; ACOG: American College of Obstetricians and Gynecologists; ANOVA: Analysis of variance; CS: Cesarean section; FT: Full term; KS: Kolmogorov-Smirnov; LPT: Late preterm;

NICU: Neonatal intensive care unit; PROM: Premature rupture of membrane; SPSS: Statistical Package for the Social Science; WHO: World Health Organization

\section{Acknowledgements}

Not applicable

\section{Authors' contributions}

AA conceived the study, participated in its design, and performed the statistical analysis. ME participated in the design of the study and drafted the manuscript. SA participated in the statistical analysis and helped to draft the manuscript. MA carried out data collection and participated in the design of the study. All authors read and approved the final manuscript.

Funding

Not applicable

Availability of data and materials

The datasets used and/or analyzed during the current study are available from the corresponding author on reasonable request.

Ethics approval and consent to participate

This study was conducted after being approved by the Research Ethics Committee, Faculty of Medicine, Fayoum University. Written consent for participation in the study was obtained from the guardians of the study subjects after being informed about the objectives of the study, as well as the examination and investigation that would be done. The confidentiality of subjects' information was maintained by assigning a code number to each participant that is known only by the investigators (Ethics committee's reference number, 12-16/03/2015).

Consent for publication

Not applicable

\section{Competing interests}

The authors declare that they have no competing interests.

\section{Author details}

${ }^{1}$ Pediatrics Department, Faculty of Medicine, Fayoum University, Fayoum, Egypt. ${ }^{2}$ Pediatrics Department, Beni Suef General Hospital, Ministry of Health, Beni Suef, Egypt.

Received: 4 July 2019 Accepted: 19 February 2020

Published online: 13 April 2020

\section{References}

1. Engle WA, Kominiarek MA (2008) Late preterm infants, early term infants, and timing of elective deliveries. Clin Perinatol 35(2):325-341

2. Tsai M-L, Lien R, Chiang M-C et al (2012) Prevalence and morbidity of late preterm infants: current status in a medical center of Northern Taiwan. Pediatrics Neonatol 53(3):171-177. https://doi.org/10.1016/j.pedneo.2012.04. 003

3. World Health Organization (2012) Born too soon: the global action report on preterm birth. World Health Organization, New York

4. Cohen-Wolkowiez M, Moran C, Benjamin DK et al (2009) Early and late onset sepsis in late preterm infants. Pediatr Infect Dis J 28(12):1052

5. Hamilton BE, Martin JA, Osterman MJK et al (2018) Vital Statistics Rapid Release; no 4: Births Provisional Data for 2017. National Center for Health Statistics (NCHS)

6. Teune MJ, Bakhuizen S, Gyamfi Bannerman C et al (2011) A systematic review of severe morbidity in infants born late preterm. Am J Obstet Gynecol 205(4):374.e371-374.e379. https://doi.org/10.1016/j.ajog.2011.07.015

7. Delnord M, Zeitlin J (2019) Epidemiology of late preterm and early term births - an international perspective. Semin Fetal Neonatal Med 24(1):3-10 https://doi.org/10.1016/j.siny.2018.09.001 
8. Delnord M, Blondel B, Zeitlin J (2015) What contributes to disparities in the preterm birth rate in European countries? Curr Opin Obstet Gynecol 27(2):133

9. Heino A, Gissler M, Hindori-Mohangoo AD et al (2016) Variations in multiple birth rates and impact on perinatal outcomes in Europe. PloS One 11(3): e0149252

10. Raju TN, Higgins RD, Stark AR et al (2006) Optimizing care and outcome for late-preterm (near-term) infants: a summary of the workshop sponsored by the National Institute of Child Health and Human Development. Pediatrics 118(3):1207-1214

11. Huff K, Rose RS, Engle WA (2019) Late preterm infants: morbidities, mortality, and management recommendations. Pediatric Clin 66(2):387-402. https:// doi.org/10.1016/j.pcl.2018.12.008

12. Santos VM, Formiga CKMR, de Mello PRB et al (2017) Late preterm infants' motor development until term age. Clinics (Sao Paulo, Brazil) 72(1):17-22. https://doi.org/10.6061/clinics/2017(01)04

13. Engle WA (2008) Surfactant-replacement therapy for respiratory distress in the preterm and term neonate. Pediatrics 121(2):419-432. https://doi.org/10. 1542/peds.2007-3283

14. Wang ML, Dorer DJ, Fleming MP et al (2004) Clinical outcomes of near-term infants. Pediatrics 114(2):372-376. https://doi.org/10.1542/peds.114.2.372

15. Escobar GJ, McCormick MC, Zupancic JA et al (2006) Unstudied infants: outcomes of moderately premature infants in the neonatal intensive care unit. Arch Dis Child Fetal Neonatal Ed 91(4):F238-F244. https://doi.org/10. 1136/adc.2005.087031

16. Stoll BJ, Hansen NI, Sanchez PJ et al (2011) Early onset neonatal sepsis: the burden of group B Streptococcal and E. coli disease continues. Pediatrics 127(5):817-826. https://doi.org/10.1542/peds.2010-2217

17. Mac Bird T, Bronstein JM, Hall RW et al (2010) Late preterm infants: birth outcomes and health care utilization in the first year. Pediatrics 126(2):e311-e319

18. Teoh PJ, Ridout A, Seed P et al (2018) Gender and preterm birth: is male fetal gender a clinically important risk factor for preterm birth in high-risk women? Eur J Obstet Gynecol Reprod Biol 225:155-159. https://doi.org/10. 1016/j.ejogrb.2018.04.025

19. Zeitlin J, Ancel PY, Larroque B et al (2004) Fetal sex and indicated very preterm birth: results of the EPIPAGE study. Am J Obstet Gynecol 190(5): 1322-1325. https://doi.org/10.1016/j.ajog.2003.10.703

20. Challis J, Newnham J, Petraglia F et al (2013) Fetal sex and preterm birth. Placenta 34(2):95-99

21. Wilms FF, Vis JY, Oudijk MA et al (2016) The impact of fetal gender and ethnicity on the risk of spontaneous preterm delivery in women with symptoms of preterm labor. J Matern Fetal Neonatal Med 29(21):3563-3569. https://doi.org/10.3109/14767058.2016.1139566

22. Verburg PE, Tucker $G$, Scheil W et al (2016) Sexual dimorphism in adverse pregnancy outcomes - a retrospective Australian population study 1981-2011. PLoS One 11(7):e0158807. https://doi.org/10.1371/journal.pone.0158807

23. Carter MF, Fowler S, Holden A et al (2011) The late preterm birth rate and its association with comorbidities in a population-based study. Am J Perinatol 28(09):703-708

24. Kozuki N, Lee AC, Silveira MF et al (2013) The associations of parity and maternal age with small-for-gestational-age, preterm, and neonatal and infant mortality: a meta-analysis. BMC Public Health 13(3):S2. https://doi.org/ 10.1186/1471-2458-13-s3-s2

25. Mandruzzato P, Cali G, Chiaffarino F et al (2013) Risk factors for late preterm births: a case-control study. Gynecol Obstet 03

26. Melamed N, Klinger G, Tenenbaum-Gavish K et al (2009) Short-term neonatal outcome in low-risk, spontaneous, singleton, late preterm deliveries. Obstet Gynecol 114(2 Part 1):253-260. https://doi.org/10.1097/ AOG.0b013e3181af6931

27. McDonald SW, Benzies KM, Gallant JE et al (2013) A comparison between late preterm and term infants on breastfeeding and maternal mental health. Matern Child Health J 17(8):1468-1477

28. Thorp JM Jr, Hartmann KE, Shadigian E (2003) Long-term physical and psychological health consequences of induced abortion: review of the evidence. Obstet Gynecol Survey 58(1):67-79. https://doi.org/10.1097/01. ogx.0000045217.37578.0b

29. De Luca R, Boulvain M, Irion $O$ et al (2009) Incidence of early neonatal mortality and morbidity after late-preterm and term cesarean delivery. Pediatrics 123(6):e1064-e1071. https://doi.org/10.1542/peds.2008-2407

30. Simões R, Cavalli RC, Bernardo WM et al (2015) Cesarean delivery and prematurity. Revista da Associação Médica Brasileira 61:489-494
31. Dey, M., Agarwal, R., Maji, D., et al. (2015). Maternal and fetal factors observed with late preterm births.

32. Bilgin BS, Uygur O, Terek D et al (2018) Reference values of anthropometric measurements in healthy late preterm and term infants. Turk J Med Sci 48: 862-872

33. de Araújo BF, Zatti H, Madi JM et al (2012) Analysis of neonatal morbidity and mortality in late-preterm newborn infants. J Pediatr 88:259-266

34. DeMauro SB, Patel PR, Medoff-Cooper B et al (2011) Postdischarge feeding patterns in early- and late-preterm infants. Clin Pediatr 50(10):957-962. https://doi.org/10.1177/0009922811409028

35. Walker M (2008) Breastfeeding the late preterm infant. J Obstet Gynecol Neonatal Nurs 37(6):692-701

36. Jain A, Mehta N (2018) A prospective study to compare morbidity and mortality profile between late preterm and term neonates from a hospital in Indore. Indian J Child Health 5(5):332-335

37. Ludwig SM (2007) Oral feeding and the late preterm infant. Newborn Infant Nurs Rev 7(2):72-75. https://doi.org/10.1053/j.nainr.2007.05.005

38. Consortium on Safe, L, Hibbard JU, Wilkins I et al (2010) Respiratory morbidity in late preterm births. JAMA 304(4):419-425. https://doi.org/10. 1001/jama.2010.1015

39. Steurer MA, Baer RJ, Keller RL et al (2017) Gestational age and outcomes in critical congenital heart disease. Pediatrics 140(4):e20170999. https://doi.org/ 10.1542/peds.2017-0999

40. Snoep MC, Jansen NJG, Groenendaal F (2018) Deaths and end-of-life decisions differed between neonatal and paediatric intensive care units at the same children's hospital. Acta Paediatrica 107(2):270-275. https://doi. org/10.1111/apa.14061

41. Darcy AE (2009) Complications of the late preterm infant. J Perinat Neonatal Nurs 23(1):78-86. https://doi.org/10.1097/JPN.0b013e31819685b6

42. Premji SS, Young M, Rogers C et al (2012) Transitions in the early-life of late preterm infants: vulnerabilities and implications for postpartum care. J Perinat Neonatal Nurs 26(1):57-68. https://doi.org/10.1097/JPN. Ob013e31823f8ff5

43. Haroon A, Ali SR, Ahmed S et al (2014) Short-term neonatal outcome in late preterm vs. term infants. J Coll Physicians Surg Pak 24(1):34

44. Blondel B, Macfarlane A, Gissler M et al (2006) General obstetrics: preterm birth and multiple pregnancy in European countries participating in the PERISTAT project. BJOG 113(5):528-535. https://doi.org/10.1111/j.1471-0528. 2006.00923.x

45. Marrocchella S, Sestilli V, Indraccolo U et al (2014) Late preterm births: a retrospective analysis of the morbidity risk stratified for gestational age. Springer Plus 3(1):114. https://doi.org/10.1186/2193-1801-3-114

46. Gyamfi-Bannerman C, Thom EA, Blackwell SC et al (2016) Antenatal betamethasone for women at risk for late preterm delivery. N Engl J Med 374(14):1311-1320. https://doi.org/10.1056/NEJMoa1516783

47. Alrais MA, Chen H-Y, Sibai BM et al (2018) Frequency of neonatal hypoglycemia after implementation of antenatal late preterm steroids use [19 K]. Obstet Gynecol 131:124S. https://doi.org/10.1097/01.AOG.0000533521. 16220.7d

48. Bailit JL, Gregory KD, Reddy UM et al (2010) Maternal and neonatal outcomes by labor onset type and gestational age. Am J Obstet Gynecol 202(3):245.e241-245.e212. https://doi.org/10.1016/j.ajog.2010.01.051

49. Glass HC, Shellhaas RA, Tsuchida TN et al (2017) Seizures in preterm neonates: a multicenter observational cohort study. Pediatric Neurol 72:19_ 24. https://doi.org/10.1016/j.pediatrneurol.2017.04.016

\section{Publisher's Note}

Springer Nature remains neutral with regard to jurisdictional claims in published maps and institutional affiliations. 